\title{
Spatial Correlation of Peak Ground Motions and Pseudo-Spectral Acceleration Based on the Sarpol-e-Zahab Mw 7.3, 2017 Earthquake Data
}

\author{
Hamid Zafarani*,1, Seyyed Mohammad Mahdi Ghafoori², Mohammad Reza Soghrat ${ }^{3}$, \\ Mahsa Shafiee ${ }^{4}$ \\ (1) International Institute of Earthquake Engineering and Seismology (IIEES), No. 26, Arghavan St., North Dibajee, \\ Farmanieh, Tehran, Iran \\ (2) $\mathrm{PhD}$, Faculty of Engineering, University of Qom, Qom, Iran \\ (3) $\mathrm{PhD}$, International Institute of Earthquake Engineering and Seismology (IIEES), Tehran, Iran \\ (4) MSC, Ale-Taha Institute of Higher Education, Tehran, Iran
}

Article history: received August 18, 2019; accepted February 3, 2020

\begin{abstract}
Ground motion intensity measures and structural responses are correlated in nearby sites. The value of this correlation relies on some parameters such as the local geology and distance between the two sites and the natural period of structures, particularly, when lifeline systems or distributed structures are of concern, the issue becomes more important. In this study, the spatial correlation of peak ground acceleration and Spectral Acceleration are evaluated as a function of inter-site separation distance for the Mw7.3 Sarpol-e-Zahab earthquake. On 12 November 2017 a large earthquake occurred near the western border of Iran. The epicenter of the earthquake was reported at $34.77 \mathrm{~N}$ and $45.76 \mathrm{E}$. Here, 192 pairs of horizontal components from the above-mentioned event and 35 of its larger aftershocks with magnitude ranging from Mw 4.0 to 7.3 are employed to evaluate the intra-event residual correlation by considering two Ground Motion Prediction Equations (GMPEs) proposed by Akkar and Bommer [2010] and Zafarani et al. [2017].

A correlation analysis is carried out through semivariogram as a powerful geostatistical tool. As a skeleton for correlation modeling, a kind of exponential model is used. According to the proposed model, the results show that the overall trend of correlation Range depends on spectral period. The results demonstrate that there is strong spatial correlation in the proposed model obtained from the Sarpol-eZahab ground motions. The model provided in this study could be employed in earthquake engineering implements such as Shakemaps [Wald et al., 1999] whenever spatial correlation models are required.
\end{abstract}

Keywords: Spatial Correlation, Aftershock, Lifeline Systems, Sarpol-e-Zahab Earthquake, Iran.

\section{Introduction}

Ground-motion prediction equation (GMPE) is a remarkable parameter in probabilistic and deterministic seismic hazard and loss evaluations [Crowley et al., 2008a]. The functional form of a ground motion model is typically a function 


\section{Hamid Zafarani et al.}

of distance, magnitude, type of soils, style of faulting and other existing parameters [Soghrat and Ziyaeifar, 2017]. GMPEs can be proposed according to the local, regional, or global databases. These models can estimate intensity measures such as peak ground acceleration (PGA), peak ground velocity (PGV) and spectral acceleration (SA) for a particular earthquake scenario. The uncertainties in the GMPEs are usually shown by the inter-event (between-events or earthquake to earthquake) and intra-event (within-event or record-to-record) variability [Sokolov and Wenzel, 2011; Zafarani and Soghrat, 2017]. Noted that, in another context uncertainties in GMPEs can be divided into epistemic and aleatory uncertainties. Epistemic uncertainty is due to the limited amount of observed data while aleatory uncertainty is because of the differences between observed and predicted data [Cimellaro et al., 2011]. Inter-event residual is the average shift of the recorded value in an earthquake from the median predicted value. Spatial correlation is usually defined for intra-event residuals. In other words, when an earthquake occurred, it is tried to find correlation in different recording stations. Therefore, the inter-event residuals excluded from analyses in this study. This is due to the fact that we lacked a sufficient number of data points to develop separate intraevent spatial correlation estimates for individual earthquakes [see Goda, 2011 for a fruitful discussion on inter-event variability of spatial correlation].

Moreover, the difference between the recorded ground motion at the specified station and the earthquake-specific median predicted is represented by intra-event residual [Chen and Faccioli, 2013]. The intra-event variability indicates that the intensity measures (IMs) at special sites are scattered around the event median. It is shown that the intraevent residuals are spatially correlated by comparing observed ground motion with a predicted relation. Also, it is resulted that with increasing distance between two stations the spatial correlation will be reduced [Wang and Takada, 2005; Goda and Hong, 2008a; Goda and Atkinson, 2010; Cimellaro et al., 2011]. Wagener et al. [2016] developed a model according to the records belongs to small to moderate seismic event for intra-event spatial correlation. They found that the correlation coefficients of short-period SA decrease quickly with increasing inter-station distance.

Estimation of spatial correlation for IMs is essential for assessment of seismic risk of distributed building portfolios, infrastructure systems and lifeline networks (such as gas or electrical networks), water supply and transportation systems. Such studies result in finding the correlation between intensity measures from different earthquakes at different sites. Several researchers investigated the consequences of spatial correlation of ground motion IMs on loss estimation for the networks mentioned above. Crowley et al. [2005] showed that intra-event correlation causes greater variability in the estimation of total earthquake loss because of a particular ground motion scenario. Some studies have represented the significant influence of intra-event spatial correlation in the probability distribution of total seismic losses [Goda and Hong, 2008b; Park et al., 2007]. In other words, disregarding and underestimating the spatial correlation can miscalculate the losses (Bazzurro and Luco 2007; Lee and Kiremidjian 2007).

The loss estimation methods are based on ground motion intensity measures in which the measures can be obtained from GMPEs. Noted that, the GMPEs can also consider the effects of spatial variations if a rich database is available and a modified regression method is essential to reach this aim [e.g. the equations proposed by Kotha et al., 2016 and Landwehr et al., 2016]. Some researchers applied only a single earthquake scenario [Crowley et al. 2008a,b; Goda and Atkinson 2009] by analyzing the intra-event correlation effects, while others studied multiple earthquakes which considered inter- and intra-event correlations [Wesson and Perkins, 2001; McVerry et al., 2004; Sokolov and Wenzel, 2011].

Some spatial correlation models have been proposed for different intensity measures. For example, according to the 1994 Northridge ground motion records the spatial correlation model of PGA is developed by Boore et al. [2003]. According to the 1999 Chi-Chi earthquake and some seismic events in Japan, Wang and Takada [2005] calculated the spatial correlation of PGV. Jayaram and Baker [2009] studied spatial correlation relations based on the 1999 Chi-Chi earthquake and several events in California. In their studies, the proposed models is based on using the wellrecorded single earthquakes.

On the other hand, spatial correlations can be modeled using the data recorded for various earthquakes such as the models proposed by Goda and Atkinson [2010] for Japan, Esposito and Iervolino [2011, 2012] for European data, Pavel and Vacareanu [2016] for Vrancea (Romania) according to intermediate-depth earthquakes. Researchers, such as Loth and Baker [2013] and Du and Wang [2013], considered the spatial cross-correlation of SAs at different structural periods. They showed the dissimilar rates of decay for correlation with site-to-site separation distance. Markhvida et al. [2018] proposed a new spatial cross-correlation model for intra-event residuals at different periods that this model used both geostatistics and principal component analysis. The effects of local site classes on the spatial correlation of IMs have been evaluated by some researchers such as Sokolov and Wenzel [2013] and Wang and $\mathrm{Du}$ [2013]. They resulted that the $\mathrm{Vs}_{30}$ is a significant parameter in the analyses. In other words, for similar site 
classes, the spatial correlation of IMs will be stronger. Heresi and Miranda [2018] studied evaluating the event-toevent uncertainty of intra-event spatial correlations and showed high event-to-event variability in the correlation model factors. They showed that magnitude of an earthquake is a significant variable of the spatial correlation model parameter unlike the site classes, tectonic region, and style of faulting. Chen and Baker [2018] described their results according to analogous spatial variation evaluation using physics-based simulations from the Cyber Shake platform. They implied that the geological condition and directivity effect are essential for modeling the spatial correlations. Worden et al. [2018] evaluated the conditional multivariate normal (MVN) distribution, and then they employed the MVN to the particular problem of ground motion interpolation. They proposed an adaptable framework to estimate different intensity measures at random locations.

Taking into account the importance of local spatial correlation models, here we investigate the correlation characteristics of the Mw 7.3 Sarpol-e-Zahab earthquake which occurred on 12 November 2017 with dozens of aftershocks. In this work, spatial correlation relations for spectral accelerations of this earthquake and its larger aftershocks are developed. For this aim, the recorded data obtained from the main event and its aftershocks earthquake are compiled and processed to find a set of corrected ground motions. In the next step, the residuals for each IM are computed using the local and regional GMPEs proposed by Zafarani et al. [2017] and Akkar and Bommer [2010]. In this work, semivariogram as geostatistical tools is used to compute spatial correlation for eight periods (ranging from zero to one second). Finally, spatial correlation models as a function of structural periods are proposed and compared with some models in the literature.

\section{Spatial correlation Model}

The computation of spatial correlation will be discussed briefly in this section. For more details, it can be referred to Jayaram and Baker [2009], Goda and Atkinson [2010] and Markhvida et al. [2018]. To model the spatial correlation, we need to describe the GMPE and Intra-event residuals which they are defined in the following. Generally, GMPEs can estimate the intensity measures in site i because of earthquake $j$ as shown in the following form:

$$
\ln Y_{i j}=\ln \overline{Y_{i j}(M, R, \theta)}+\varepsilon_{i j}+\eta_{j}
$$

Where the predicted median of ground motions is shown by $\overline{Y_{i j}(M, R, \theta)}$. It depends on Magnitude (M), source-tosite distance (R) and other available parameters $(\theta)$ such as type of soils and style of faulting. $Y_{j}$ is the observed ground motion parameter of interest such as PGA, PGV or SA. Also, $\varepsilon_{i j}$ and $\eta_{j}$ are intra-event and inter-event residuals with zero mean and standard deviations of $\sigma_{i j}$ and $\tau_{j}$, respectively. Noted that the overall standard deviation $\left(\sigma_{T}\right)$ is computed by equation (2):

$$
\sigma_{T}=\sqrt{\sigma_{i j}^{2}+\tau_{j}^{2}}
$$

Generally, GMPEs have been proposed according to different database. So, three categories can be considered for these equations including models proposed specifically for the Iranian plateau, the ones proposed for the Middle East and Europe region and global ground motion relations proposed by the "Next Generation of Ground-Motion Attenuation Models" (NGA). In this study, two models proposed by Zafarani et al. [2017] and Akkar and Bommer [2010] are employed for estimating the predicted values for PGA and SA. Akkar and Bommer [2010] developed the GMPE for the prediction of PGA and SA in the periods up to $4 \mathrm{~s}$ using 532 accelerograms according to the MiddleEast and Europe database. Zafarani et al. [2017] developed the model for the prediction of PGA and SA up to $4 \mathrm{~s}$ using a total of 1551 free-field acceleration time histories recorded at Iranian plateau.

The semivariogram, which applied to find the dissimilarity or decorrelation between data [Cressie, 1993], can be computed assuming the hypothesis of second-order stationary and isotropy using equation (3).

$$
\gamma(h)=a[1-\rho(h)]
$$

where $a$ and $\rho(h)$ is the sill and the correlation coefficient between intra-event residuals at two different sites separated by $\mathrm{h}$ distance, respectively. 


\section{Hamid Zafarani et al.}

An assessment of the experimental semivariogram for given IM (e.g. SA) based on dual empirical observations at two adjacent sites $\mathrm{x}$ and $x+h$ is obtained as follows:

$$
\hat{\gamma}(h)=\frac{1}{2|N(h)|} \sum_{i=1}^{N(h)}[\varepsilon(v)-\varepsilon(v+h)]^{2}
$$

Here $\hat{\gamma}(h)$ is the estimated stationary semivariogram, $\varepsilon(v)-\varepsilon(v+h)$ represents the difference between intraevent residuals at sites with distance $h ; N(h)$ is the set of pairs of adjacent sites separated by the same distance $h$, and $|N(h)|$ is the cardinal of $N(h)$. The formula is resulted from the method-of-moments and is referred to as the classical estimator [Matheron, 1962]. Because the summation is over a squared term, the estimator will be seriously affected by typical observations (LJ Young and J Young, 2013). Therefore, Cressie and Hawkins [1980] developed a more robust estimator of semivariograms, which is less sensitive to outliers, as follows:

$$
\hat{\gamma}(h)=\frac{\left\{\sum_{i=1}^{N(h)}[\varepsilon(v)-\varepsilon(v+h)]^{1 / 2}\right\}^{4}}{2|N(h)|\left(0.457+\frac{0.494}{|N(h)|}\right)}
$$

Note that in the above formulation a common semivariogram in variant through earthquakes is assumed for different events. However, individual events are treated separately in computing the empirical semivariogram, that is, $\varepsilon(v)-\varepsilon(v+h)$ differences are taken considering only intra-event residuals from the same earthquake without mixing up the events [see Figure 4 in Esposito and Iervolino, 2011].

The recorded logarithmic intensity measures follow a lognormal distribution that may be $\operatorname{shown}$ as $\ln Y_{i j}=N\left(\ln \bar{Y}_{i j} ; \sigma_{T}\right)$. As a result, the normalized intra-event residuals $\left(\bar{\varepsilon}_{i j}\right)$ can be calculated as follows:

$$
\bar{\varepsilon}_{i j}=\frac{\varepsilon_{i j}}{\sigma_{i j}} \approx \frac{\ln Y_{i j}-\ln Y_{i j}(M, R, \theta)}{\sigma_{i j}}
$$

Noted that, the normalized intra-event residuals are approximated by equation (6). We know that inter-event residuals are constant during a seismic event for each site, this approximation is reasonable and does not change the results.

The spatial correlation of the normalized intra-event residuals can be studied using semivariogram. Semivariogram is a geostatistical tool used to quantify the degree of divergence between observations as a function of distance. In other words, the semivariogram is used to find the dissimilarity or decorrelation between data.

Because normalized intra-event residuals $\bar{\varepsilon}_{i j}$ have unit variance, we keep away from the evaluation of the sill, as it should be equal one [Jayaram and Baker, 2009]. Consequently, equation (3) becomes equation (7), where the superscript shows an empirical computation:

$$
\gamma(h)=1-\rho(h)
$$

After calculation of semivariograms in many discrete points, for practical usage it is important to fit a continuous function to the resulted measures, because of calculating semivariogram values for any probable separation $\mathrm{h}$. Several correlation models have been proposed in the literature which they can be considered Gaussian model, exponential model and spherical model as shown in equation 8 .

$$
\begin{gathered}
\gamma(h)=1-\exp \left(-3 h^{2} / b^{2}\right) \\
\gamma(h)=1-\exp (-3 h / b) \\
\gamma(h)=\frac{3}{2}(h / b)-\frac{1}{2}(h / b)^{3} \quad \text { if } h \leq b \\
=\text { a otherwise }
\end{gathered}
$$

where $b$ is Range of the semivariogram function. The exponential model, as a most common one in literature is used for further analysis in this study. 


\section{Strong motion data}

The Iranian plateau is one of the tectonically active regions which located along the Alpine-Himalayan orogenic belt where many large seismic events occurred in this region [Zafarani and Soghrat, 2017].

The Iranian strong motion network (ISMN) of the Building and Housing Research Center (BHRC) records the strong ground motion data. This network was equipped with Kinemetrics SMA-1 analog accelerographs, which have been gradually replaced and densified with SSA-2 and CMG-5TD digital instruments. Since 1975, more than 1100 stations are available across the country which recorded more than 10,000 accelerograms until now.

On 12 November 2017, an earthquake with moment magnitude of 7.3 occurred in the Zagros seismotectonic zone, near the western border of Iran (see Figure 1). This event happened near Sarpol-e-Zahab city. The epicenter was reported to be at $34.77 \mathrm{~N}$ and $45.76 \mathrm{E}$ by the Iranian Seismological Center (IRSC) at depth of $18 \mathrm{~km}$. Noted that this event is the largest earthquake over the last 100 years in the Zagros region [Farzanegan et al., 2017]. This event caused numerous landslides and building damages which leads to more than 600 deaths and 7000 homeless. People sensed this earthquake at distances about several hundred kilometres such as Tabriz and Arak. The maximum horizontal PGA of 0.69g was recorded at the Sarpol-e-Zahab station. In this study, we considered the main earthquake and its larger aftershocks (35 aftershocks with Mw more than 4.0 with at least two high-quality records) which their characteristics are shown in Table 1.

In the further analysis, the site categorization is considered according to the characteristics of the top $30 \mathrm{~m}$ $\left(\mathrm{Vs}_{30}\right)$ of the soil column regarding to the Iranian code of practice for standard seismic resistantdesign of buildings, StandardNo.2800. This standard classifies the sites in four classes including: I - Vs30>750, I I- $375<$ Vs30<750, III - $175<$ Vs30<375 and IV - Vs30<175. Figure 2 illustrated the distribution of magnitude and distance for the collocated database.

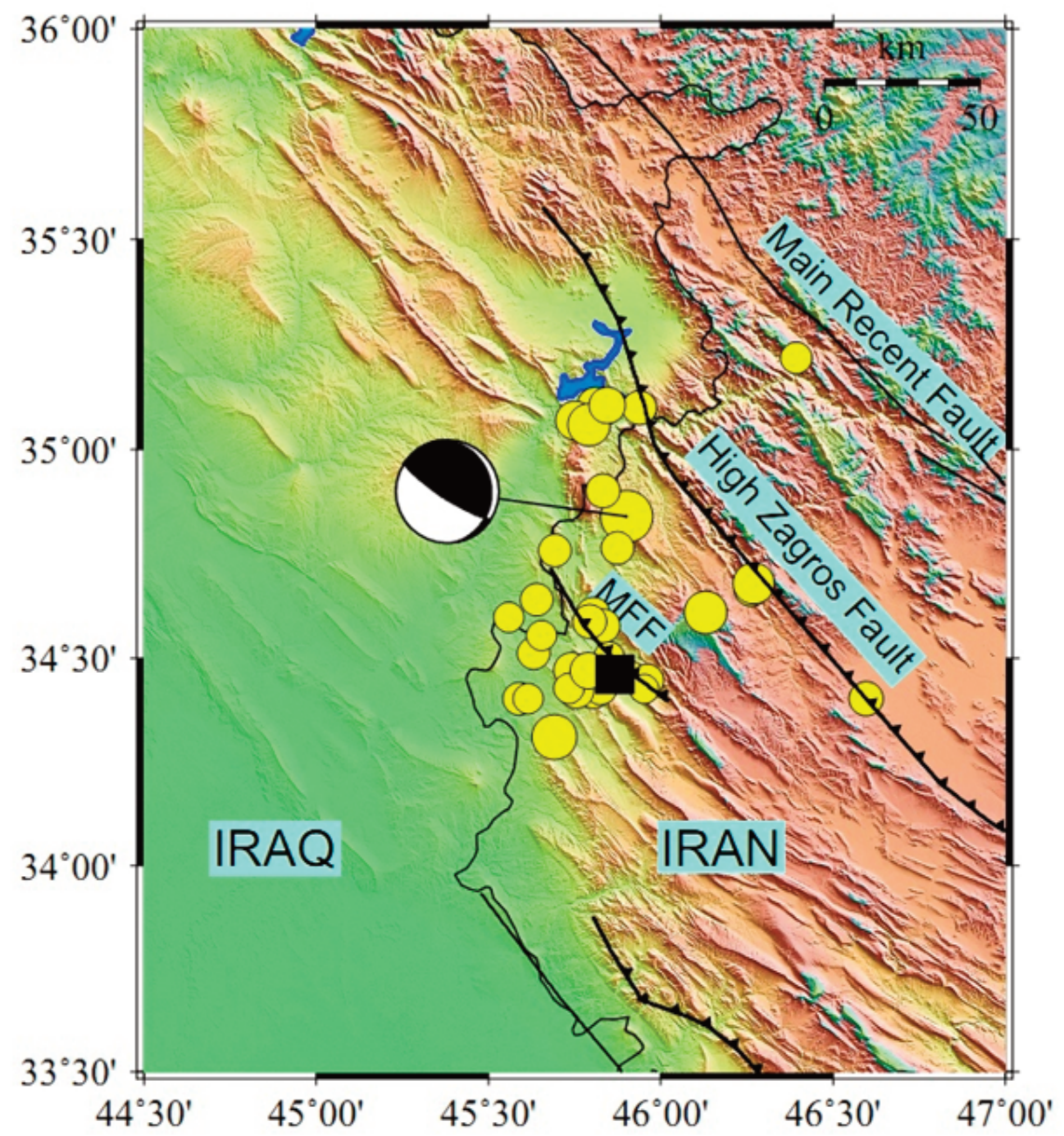

Figure 1. Distribution of the study earthquakes in western Iran, the square indicates Sarpol-e-Zahab city, MFF: Main Front Fault. 
Hamid Zafarani et al.

\begin{tabular}{|c|c|c|c|c|c|c|c|}
\hline Number & Date & Time & Lat. (deg) & Lon. (deg) & Depth (km) & Mw & $\begin{array}{l}\text { Number of } \\
\text { Records }\end{array}$ \\
\hline 1 & $11 / 12 / 2017$ & $18: 18: 16$ & 34.84 & 45.9 & 18 & 7.3 & 59 \\
\hline 2 & $12 / 11 / 2017$ & $20: 42: 45$ & 34.466 & 45.865 & 8 & 4.3 & 2 \\
\hline 3 & $12 / 11 / 2017$ & $21: 33: 22$ & 34.605 & 45.803 & 8 & 4.7 & 2 \\
\hline 4 & $13 / 11 / 2017$ & $4: 27: 55$ & 34.421 & 45.804 & 10 & 4.9 & 2 \\
\hline 5 & $13 / 11 / 2017$ & $4: 36: 12$ & 34.428 & 45.824 & 10 & 4.6 & 2 \\
\hline 6 & $13 / 11 / 2017$ & $9: 19: 28$ & 34.421 & 45.755 & 8 & 4.9 & 2 \\
\hline 7 & $13 / 11 / 2017$ & $13: 12: 37$ & 34.471 & 45.74 & 8 & 4.9 & 3 \\
\hline 8 & $14 / 11 / 2017$ & 1:08:45 & 34.457 & 45.911 & 8 & 4.3 & 2 \\
\hline 9 & $15 / 11 / 2017$ & $7: 11: 19$ & 34.504 & 45.849 & 8 & 4.3 & 4 \\
\hline 10 & $15 / 11 / 2017$ & $15: 20: 37$ & 34.589 & 45.588 & 10 & 4.6 & 3 \\
\hline 11 & $16 / 11 / 2017$ & $0: 16: 15$ & 34.403 & 45.615 & 9 & 4.3 & 3 \\
\hline 12 & $16 / 11 / 2017$ & 1:09:19 & 34.598 & 45.558 & 8 & 4.3 & 3 \\
\hline 13 & $18 / 11 / 2017$ & $4: 12: 15$ & 34.512 & 45.631 & 13 & 4.6 & 2 \\
\hline 14 & 19/11/2017 & 1:07:33 & 34.447 & 45.96 & 8 & 4.5 & 2 \\
\hline 15 & $19 / 11 / 2017$ & $2: 59: 15$ & 34.426 & 45.951 & 10 & 4.1 & 2 \\
\hline 16 & $19 / 11 / 2017$ & 6:19:48 & 35.218 & 46.392 & 9 & 4.4 & 2 \\
\hline 17 & $20 / 11 / 2017$ & $15: 36: 00$ & 34.901 & 45.832 & 12 & 4.7 & 3 \\
\hline 18 & $21 / 11 / 2017$ & $17: 46: 19$ & 34.554 & 45.653 & 10 & 4.3 & 2 \\
\hline 19 & $22 / 11 / 2017$ & $20: 34: 03$ & 34.758 & 45.693 & 10 & 4.5 & 2 \\
\hline 20 & $26 / 11 / 2017$ & $5: 47: 31$ & 34.578 & 45.832 & 15 & 4.7 & 3 \\
\hline 21 & $1 / 12 / 2017$ & $20: 17: 05$ & 34.403 & 46.596 & 10 & 4.8 & 2 \\
\hline 22 & 6/12/2017 & $5: 53: 43$ & 35.105 & 45.81 & 8 & 5 & 2 \\
\hline 23 & 6/12/2017 & $7: 57: 41$ & 34.64 & 45.64 & 8 & 4.6 & 4 \\
\hline 24 & 8/12/2017 & $1: 55: 00$ & 35.1 & 45.938 & 10 & 4.7 & 2 \\
\hline 25 & $8 / 12 / 2017$ & 7:39:43 & 34.428 & 45.733 & 6 & 4.2 & 2 \\
\hline 26 & $11 / 12 / 2017$ & 14:09:56 & 35.07 & 45.75 & 20 & 5.4 & 13 \\
\hline 27 & $11 / 12 / 2017$ & 14:09:56 & 35.06 & 45.792 & 10 & 5.9 & 2 \\
\hline 28 & $11 / 12 / 2017$ & $14: 42: 40$ & 35.106 & 45.844 & 10 & 5 & 3 \\
\hline 29 & $19 / 12 / 2017$ & $9: 15: 47$ & 34.764 & 45.874 & 8 & 4.5 & 2 \\
\hline 30 & $20 / 12 / 2017$ & 20:01:06 & 34.467 & 45.826 & 8 & 4.8 & 5 \\
\hline 31 & $20 / 12 / 2017$ & $20: 22: 06$ & 34.665 & 46.262 & 6 & 4.8 & 2 \\
\hline 32 & $21 / 12 / 2017$ & $2: 50: 14$ & 34.588 & 45.793 & 12 & 4.7 & 2 \\
\hline 33 & $6 / 1 / 2018$ & $15: 22: 07$ & 34.47 & 45.79 & 14 & 5.1 & 10 \\
\hline 34 & $22 / 07 / 2018$ & $10: 07: 25$ & 34.68 & 46.27 & 10 & 5.7 & 15 \\
\hline 35 & $25 / 08 / 2018$ & $22: 13: 25$ & 34.61 & 46.13 & 12 & 6 & 25 \\
\hline 36 & $25 / 11 / 2018$ & $16: 37: 31$ & 34.31 & 45.69 & 16 & 6.3 & 31 \\
\hline
\end{tabular}

Table 1. The earthquakes considered in this work.

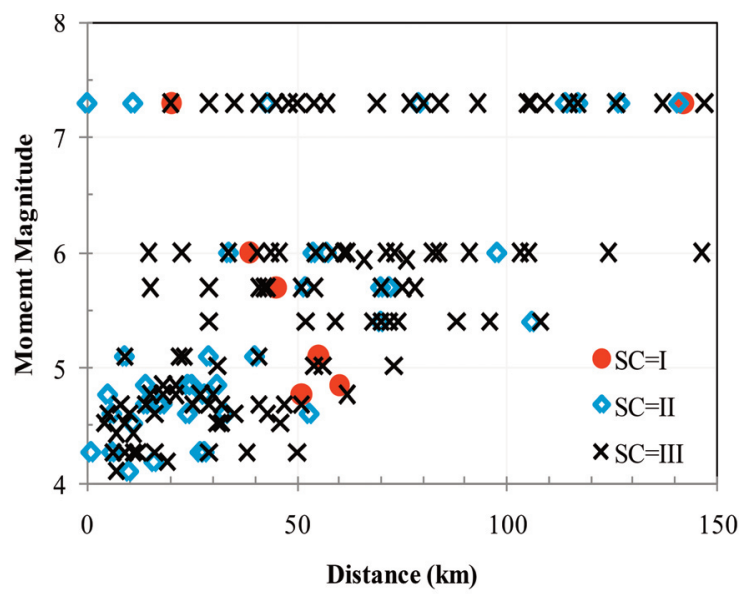

Figure 2. Distribution of moment magnitude-distance and corresponding site classes. 


\section{Evaluation of Spatial correlations and results}

The predicted measures for the horizontal component of ground motions were calculated at different periods using the model developed by Zafarani et al. [2017] and Akkar and Bommer [2010]. The geometric mean of horizontal components in the GMPEs is considered in the both proposed models. According to previous sections, computing the intra-event residuals is the first step in the analyses. Figure 3 shows the intra-event residuals for the relations proposed by Zafarani et al. [2017] and Akkar and Bommer [2010] at four different periods including T = 0 (or PGA), 0.3, 0.6 and 1s.

After calculation of the residuals, the Ranges of semivariograms computed using the earthquakes introduced in the strong motion data section. Journel and Huijbregts [1978] have been suggested half of the maximum distance between sites in the dataset and they recommended to consider the number of bins so that there are at least 30 pairs per bin. Different distance bins are tried in this study for the analyses. Different bin widths from 1 to $7 \mathrm{~km}$ were tried, and finally the bin of $7 \mathrm{~km}$ and the maximum distance of source-to-site of $120 \mathrm{~km}$ was considered in the present study. Figure 4 demonstrates the number of pairs in each bin according to separation distances. Noted that, for fitting experimental values, the exponential model was chosen for the analyses that were used in similar studies [e.g., Jayaram and Baker, 2009; Esposito and Iervolino, 2011, 2012].
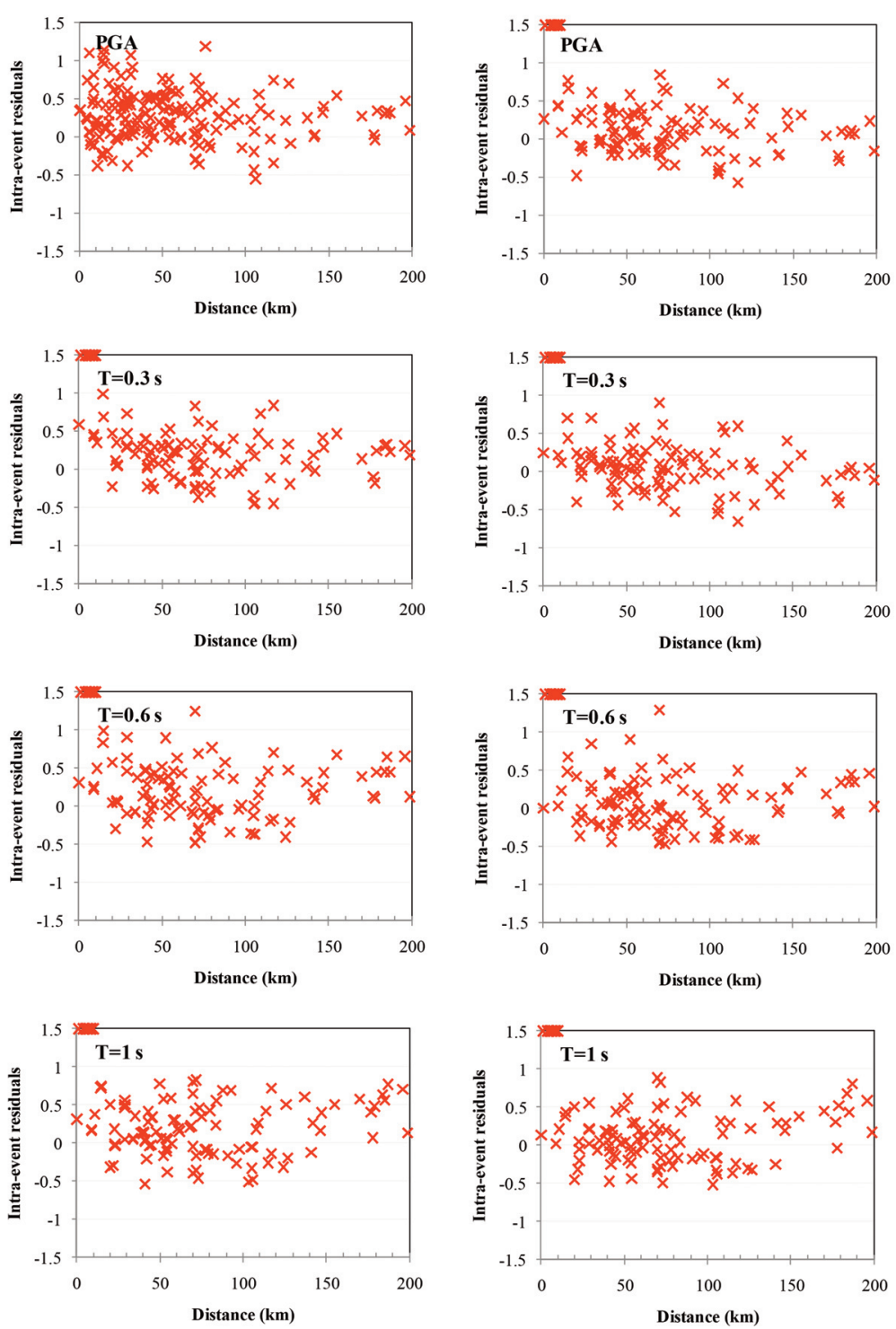

Figure 3. Intra-event residuals for PGA, and SA at $\mathrm{T}=0.3,0.6$ and 1 sec according to the model proposed by Zafarani et al. [2017], left column and Akkar and Bommer [2010], right column. 


\section{Hamid Zafarani et al.}

By assuming the nugget effect in the modeling, the Range $b$ (equation (8-b)) is required to determine. To estimate the $\mathrm{b}$ some methods such as least square fit, weighted least square fit, and the manual fitting method has been proposed in the literature [see Jayaram and Baker, 2009; Du and Wang, 2013; Wang and Du, 2013]. In this study, we used the least square method to fit the exponential model (equation (8-b)) on provided data obtained from the robust estimator.

Table 2 shows the model parameters for the exponential model (equation (8-b)) obtained from using the robust estimator and the classic estimator results. As observed in previous studies, such as Esposito and Iervolino [2012], the results of two estimators are not so different and therefore the only the robust estimator results are considered.
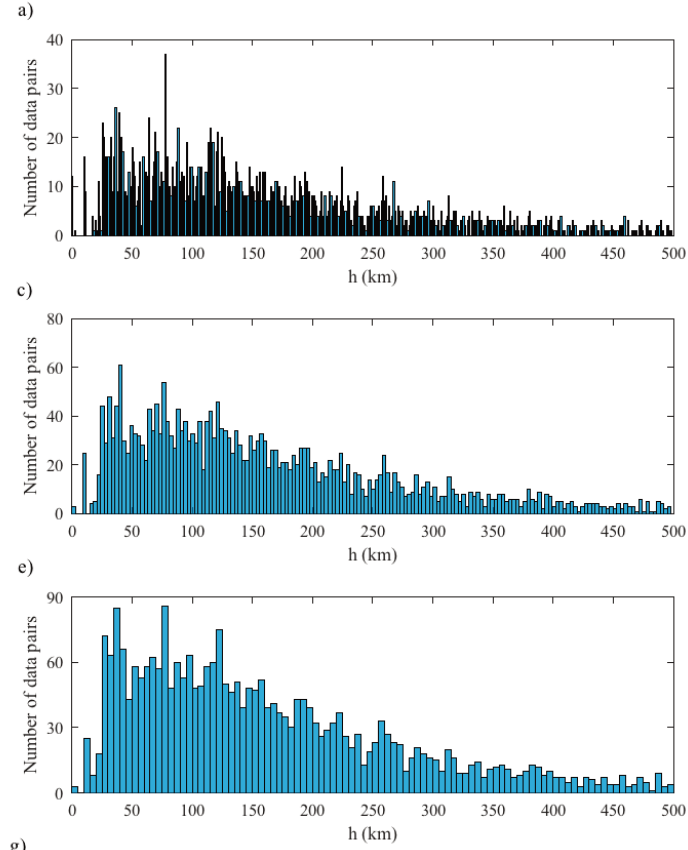

g)

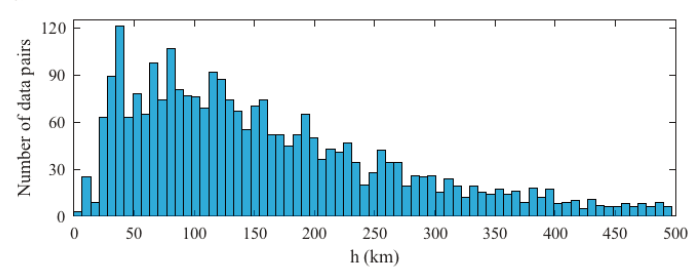

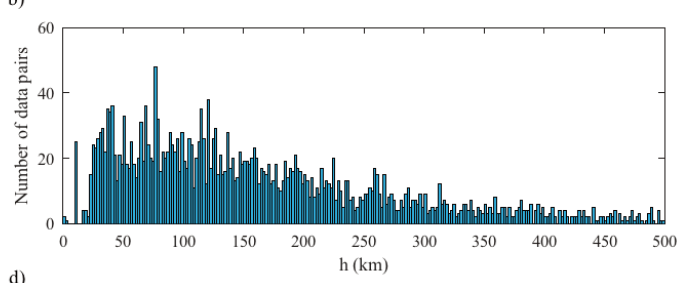
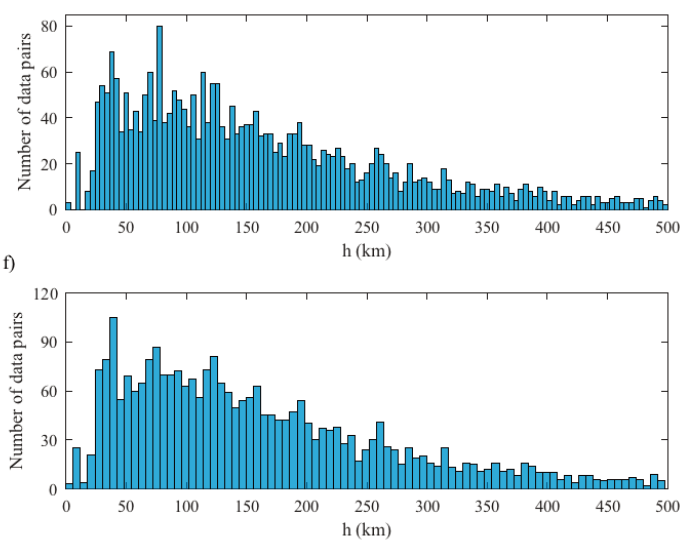

Figure 4. The number of data pairs as a function of site-to-site separation distance for different bin width a) $1 \mathrm{~km}, \mathrm{~b}) 2 \mathrm{~km}$, c) $3 \mathrm{~km}$, d) $4 \mathrm{~km}$, e) $5 \mathrm{~km}$, f) $6 \mathrm{~km}, \mathrm{~g}) 7 \mathrm{~km}$.

General trend and the values of estimated Ranges at different periods for both Akkar and Bommer [2010] and Zafarani et al. [2017] GMPEs and for both estimators are quite similar. As observed in previous studies, such as Esposito and Iervolino [2012], the results of two estimators are not so different and therefore only the robust estimator results are considered.

Figures $5 \mathrm{a}$ and $5 \mathrm{~b}$ plot the estimated Ranges by Robust estimator versus periods for Akkar and Bommer, [2010] and Zafarani et al. [2017] GMPEs, respectively. The estimated Ranges by Zafarani et al. [2017] GMPE are higher, in general than estimated Ranges according to the model proposed by Akkar and Bommer [2010]. Because low spectral periods (high frequencies) are investigated in this study, there is no clear trend between Ranges and periods for both models proposed by Akkar and Bommer [2010] and Zafarani et al. [2017]. Thisobservation (no clear trend between Ranges and periods) has been consistent with past studies in the topics of spatial correlation of spectral acceleration [Esposito and Iervolino, 2012; Zerva and Zervas, 2002]. As Jayaram and Baker [2009] expressed in their study, there are significant differences in the obtained Ranges depending on the ground-motion time histories 
Spatial Correlation of Spectral Acceleration

\begin{tabular}{|c|c|c|c|}
\hline \multirow{2}{*}{ GMPE } & \multirow{2}{*}{ Period (s) } & $\begin{array}{l}\text { Exponential Model With } \\
\text { Classic Estimator }\end{array}$ & $\begin{array}{l}\text { Exponential Model With } \\
\text { Robust Estimator }\end{array}$ \\
\hline & & Range (km) & Range (km) \\
\hline \multirow{9}{*}{ Akkar and Bommer [2010] } & PGA & 18.76 & 16.93 \\
\hline & 0.1 & 35.73 & 46.02 \\
\hline & 0.2 & 4.94 & 29.53 \\
\hline & 0.3 & 22.00 & 20.94 \\
\hline & 0.4 & 15.16 & 14.33 \\
\hline & 0.5 & 21.20 & 15.79 \\
\hline & 0.7 & 26.23 & 19.90 \\
\hline & 0.9 & 41.91 & 41.93 \\
\hline & 1.0 & 34.36 & 59.52 \\
\hline \multirow{9}{*}{ Zafarani et al. [2017] } & PGA & 29.67 & 36.27 \\
\hline & 0.1 & 38.38 & 45.24 \\
\hline & 0.2 & 6.34 & 30.27 \\
\hline & 0.3 & 37.50 & 26.15 \\
\hline & 0.4 & 20.20 & 15.92 \\
\hline & 0.5 & 26.05 & 28.72 \\
\hline & 0.7 & 36.93 & 43.50 \\
\hline & 0.9 & 61.28 & 115.00 \\
\hline & 1.0 & 55.82 & 120.00 \\
\hline
\end{tabular}

Table 2. Estimated Ranges for spectral acceleration as a function of period.

used at short periods (below $1 \mathrm{~s}$ ). There is no certain trend in the study for whole periods less than 1 sec which the most structures in the studied region are in this range of period. According to the results, three segments can be considered to investigate the trend of correlation Ranges including $0 \leq \mathrm{T} \leq 0.1 \mathrm{~s}, 0.1 \mathrm{~s}<\mathrm{T} \leq 0.4 \mathrm{~s}$, and $0.4 \mathrm{~s}<\mathrm{T} \leq 1.0 \mathrm{~s}$. The Ranges in the first part is increasing up to $\mathrm{T}=0.1 \mathrm{~s}$ which is in harmony with Du and Wang [2013], and Esposito and Iervolino [2012]. The Ranges in the second segment has a decreasing trend with the increasing period which has been observed in recent studies such as Du and Wang [2013], Jayaram and Baker [2008, 2009], and Zerva and Zervas [2002]. The trend of Ranges in third part is incremental similar to the model developed by Du and Wang [2013], and Jayaram and Baker [2009].

Experimental semivariogram values using classical estimator and exponential fitted model at different period by considering the model proposed by Akkar and Bommer [2010] shown in Figure 6.

Moreover, experimental semivariogram values using classical estimator and exponential fitted model at different period by considering the model proposed by Zafarani et al. [2017] shown in Figure 7.

It seems that the values estimated by classic and robust estimators are similar except some cases (as shown in Figures 6 and 7). The classic estimator can be affected by undesirable effects while the robust estimator proposed by Cressie and Hawkins [1980] is less sensitive to outliers. Furthermore, an exponential model is fitted to the results of Robust estimator according to the study of Esposito and Iervolino [2012]. 


\section{Hamid Zafarani et al.}
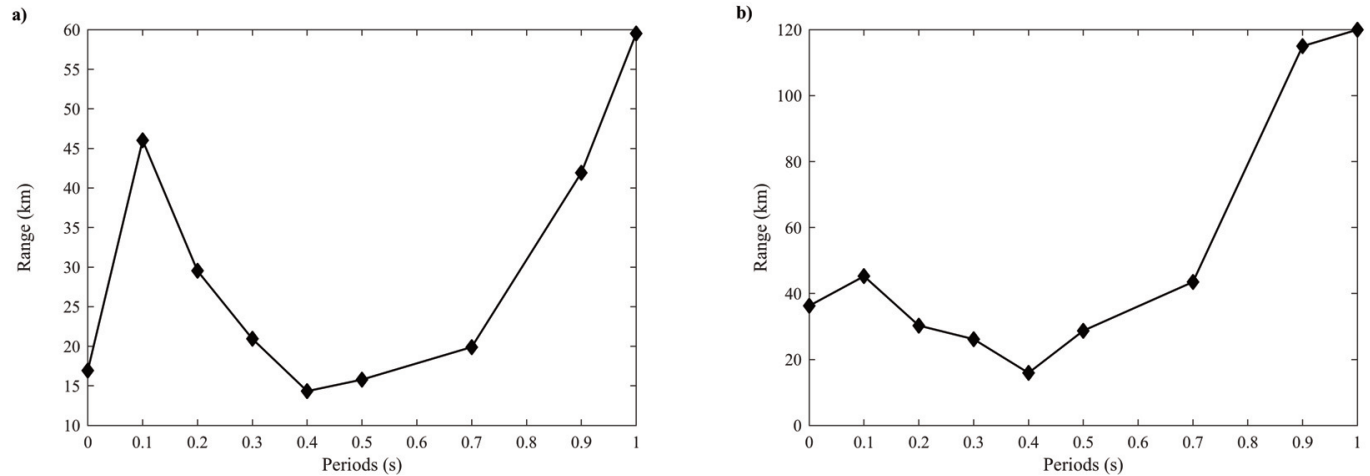

Figure 5. Estimated Ranges by Robust estimator versus periods for a) Akkar and Bommer, [2010] GMPE and b) Zafarani et al. [2017] GMPE.

Finally, in order to show the regional dependency of the correlation model, a comparison with some correlation models in California, Italy, Europe, Taiwan and Turkey is done in Figure 8. Figure 8 shows a comparison between correlation model fitted to the Sarpol-e-Zahab earthquake data with using two different GMPEs and those models from pan-European data [Esposito and Iervolino, 2012], Italy [Esposito and Iervolino, 2012], California and Taiwan [Jayaram and Baker, 2009], California [Goda and Hong, 2008] and Turkey [Wagener et al., 2016].

a)

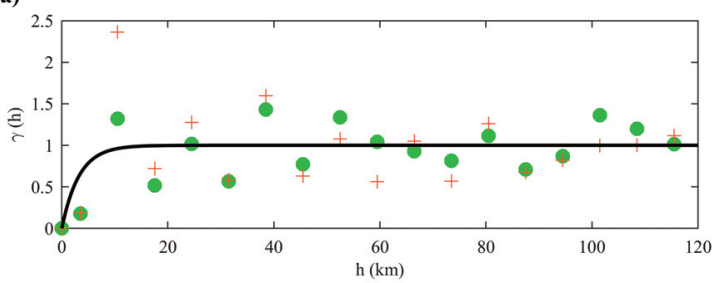

c)

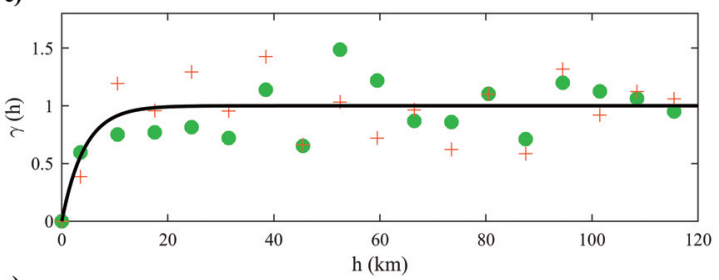

e)
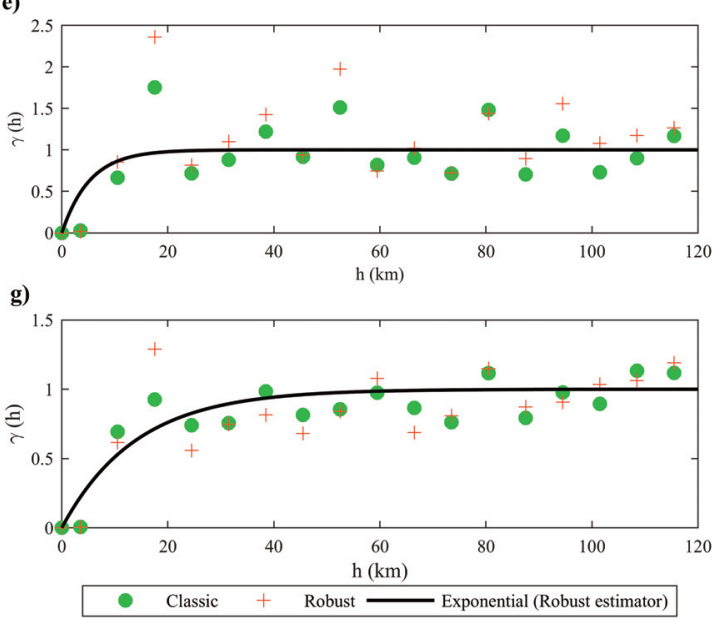

b)

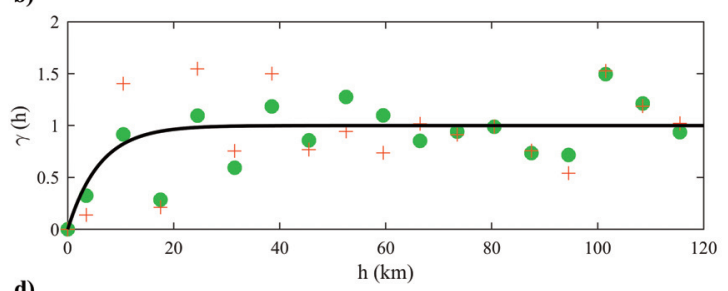

d)
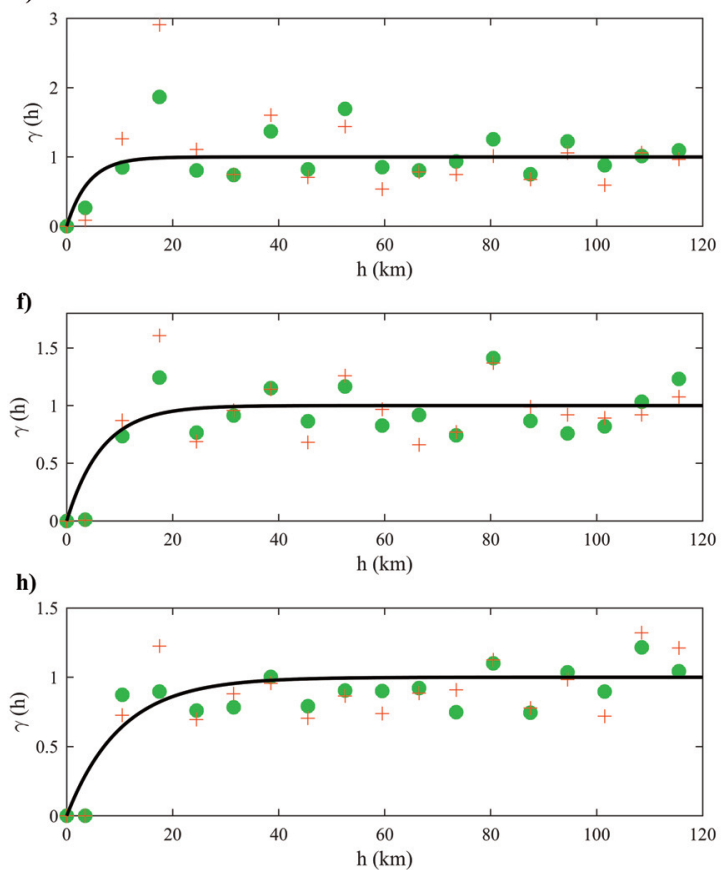

Figure 6. Experimental semivariogram values using classical estimator and exponential fitted model at different periods a) $\mathrm{T}=0 \mathrm{~s}, \mathrm{~b}) \mathrm{T}=0.1 \mathrm{~s}, \mathrm{c}) \mathrm{T}=0.3 \mathrm{~s}, \mathrm{~d}$ ) $\mathrm{T}=0.4 \mathrm{~s}, \mathrm{e}) \mathrm{T}=0.5 \mathrm{~s}, \mathrm{f}) \mathrm{T}=0.7 \mathrm{~s}, \mathrm{~g}) \mathrm{T}=0.9 \mathrm{~s}, \mathrm{~h}) \mathrm{T}=1.0 \mathrm{~s}$, by considering the model proposed by Akkar and Bommer [2010]. 
a)

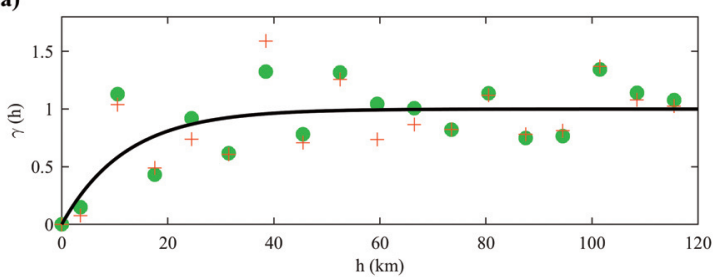

c)
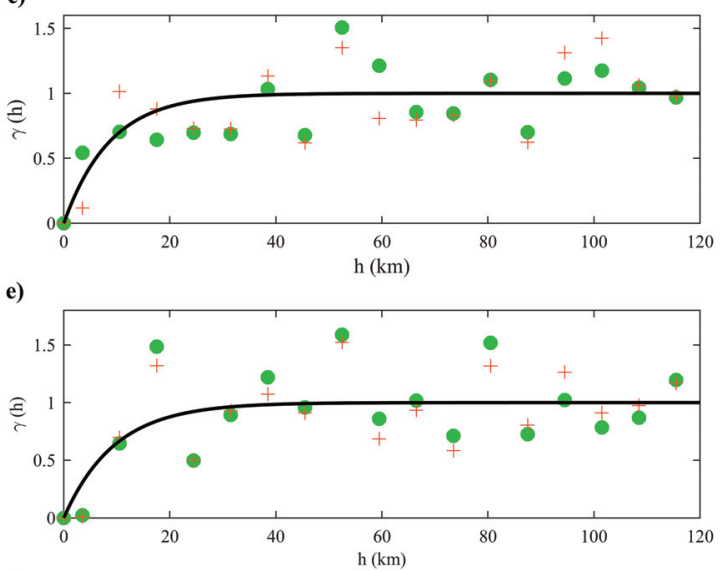

g)

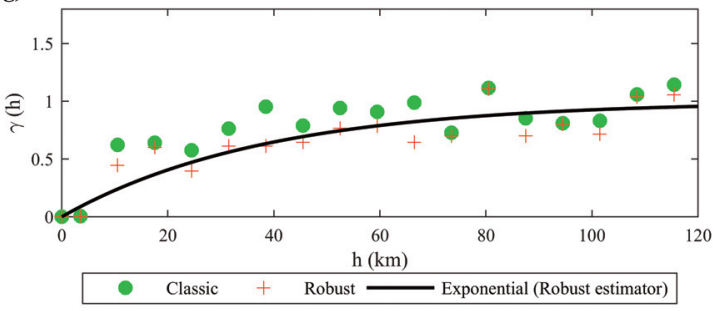

b)
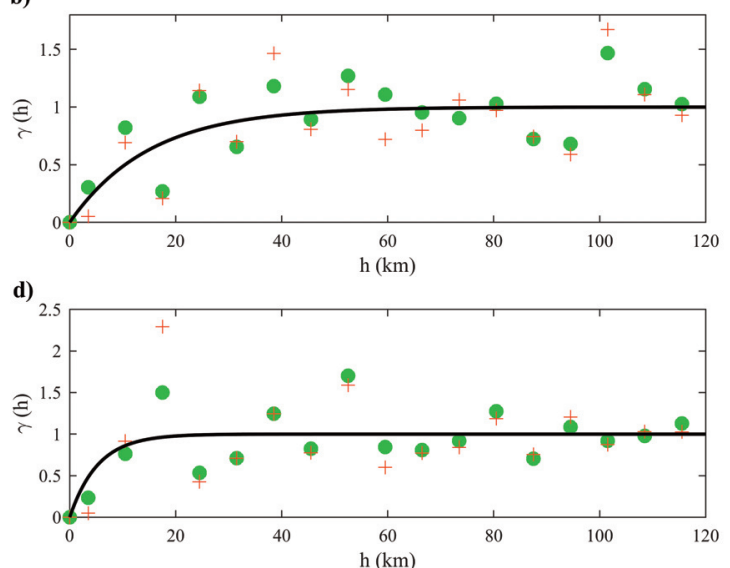

f)

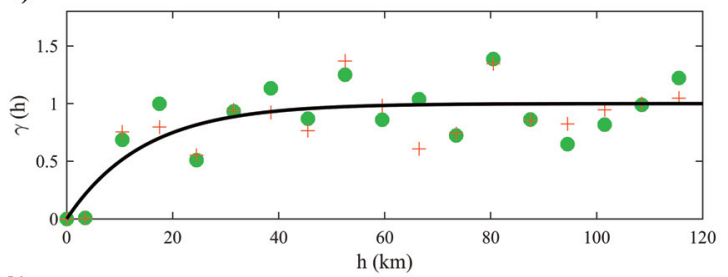

h)

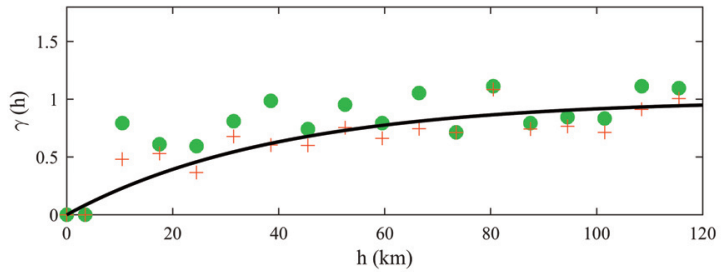

Figure 7. Experimental semivariogram values using classical estimator and exponential fitted model at different periods a) $\mathrm{T}=0 \mathrm{~s}, \mathrm{~b}) \mathrm{T}=0.1 \mathrm{~s}, \mathrm{c}) \mathrm{T}=0.3 \mathrm{~s}, \mathrm{~d}$ ) $\mathrm{T}=0.4 \mathrm{~s}$, e) $\mathrm{T}=0.5 \mathrm{~s}, \mathrm{f}) \mathrm{T}=0.7 \mathrm{~s}, \mathrm{~g}$ ) $\mathrm{T}=0.9 \mathrm{~s}, \mathrm{~h}$ ) $\mathrm{T}=1.0 \mathrm{~s}$, by considering the model proposed by Zafarani et al. [2017].

The ESD data in this Figure, correspond to records used in the study of Esposito and Iervolino [2012] and the Akkar and Bommer [2010]. ITACA dataset considered by Esposito and Iervolino [2012] contains 763 ground motions from 97 events with Mw 4.0-6.9. Goda and Hong [2008] used 592 ground motions from 39 events in Western North America. Jayaram and Baker [2009] employed the ground motion records of seven earthquakes including Anza earthquake, Alum Rock earthquake, Parkfield earthquake, Chi-Chi earthquake, Northridge earthquake, Big Bear City earthquake and Chino Hills earthquake. The data used in Wagener et al. [2016] included 372 records of eight earthquakes that were obtained from the Istanbul earthquake which occurred between 2003 and 2013 with Mw 3.5-4.8. Generally, California, Italy, Europe, Taiwan and Turkey data shows less correlation than Sarpol-e-Zahab earthquake data which attenuate more rapidly. This may be due to the different characteristics of seismic sources, e.g. different stress drops, and also different crustal properties.

A final Figure is prepared to compare correlation model of PGA with respects to separation distance, for different seismic regions of the world. Specifically, in two studies including Wang and Takada [2005] and Du and Wang [2013] the correlation function was obtained for PGA. In Figure 9 (a) and (b), the obtained correlation function in this study with the both GMPEs is compared with the correlation functions obtained for the earthquake ground motions used in Du and Wang [2013] and Wang and Takada [2005], respectively. Wang and Takada [2005] used records of six earthquakes in Japan including Tottori-ken Seibu (315 records), Geiyo (370 records), Miyagi-ken-oki (230 records), Miyagi-ken Hokubu (246 records), Tokachi-oki (287 records) and Mid Niigata-prefecture (374 records). These events occurred between 2000 and 2004 with Mw 6.2-8.0. They applied Midorikawa-Ohtake GMPE in their study. Du and Wang [2013] used U.S., Japan and Taiwan earthquakes records. 


\section{Hamid Zafarani et al.}

The database include Chi-Chi (381 records), Northridge (149 records), Parkfield (89 records), Anza (111 records), Alum Rock (161 records), Chino Hills (337 records), Tottori (112 records), Niigata (134 records) and Chuetsu (114 records) earthquakes records. The correlation functions of PGA obtained for Sarpol-e-Zahab earthquake data by both GMPE are consistent with the results of the earthquake data used in the Wang and Takada [2005] and $\mathrm{Du}$ and Wang [2013]. The correlation in the model proposed by Akkar and Bommer [2010] decays with distance more rapidly. Also as shown in Figure 9a, the result of proposed models in this study [using GMPEs proposed by Akkar and Bommer, 2010, and Zafarani et al., 2019] are consistent with Du and Wang [2103] including ground motions from nine other earthquakes occurred in Taiwan, California and Japan. Comparison between the results of our models with Wang and Takeda [2005] in Figure 9b shows that the model proposed by Zafarani et al. [2017] is in the upper limit while the model proposed by Akkar and Bommer (2010) is in lower limit. From the epistemic uncertainty point of view, we recommend to use both correlation models in practical applications.

The results of this study show that there is strong spatial correlation in the proposed models obtained from the Sarpol-e-Zahab earthquake ground motions. Therefore, these models should be used for hazard analyses and risk assessment studies in this region. Noted that, ignoring the spatial correlations in hazard evaluations for distributed structures (such as lifelines) can lead to significant distortion of results.
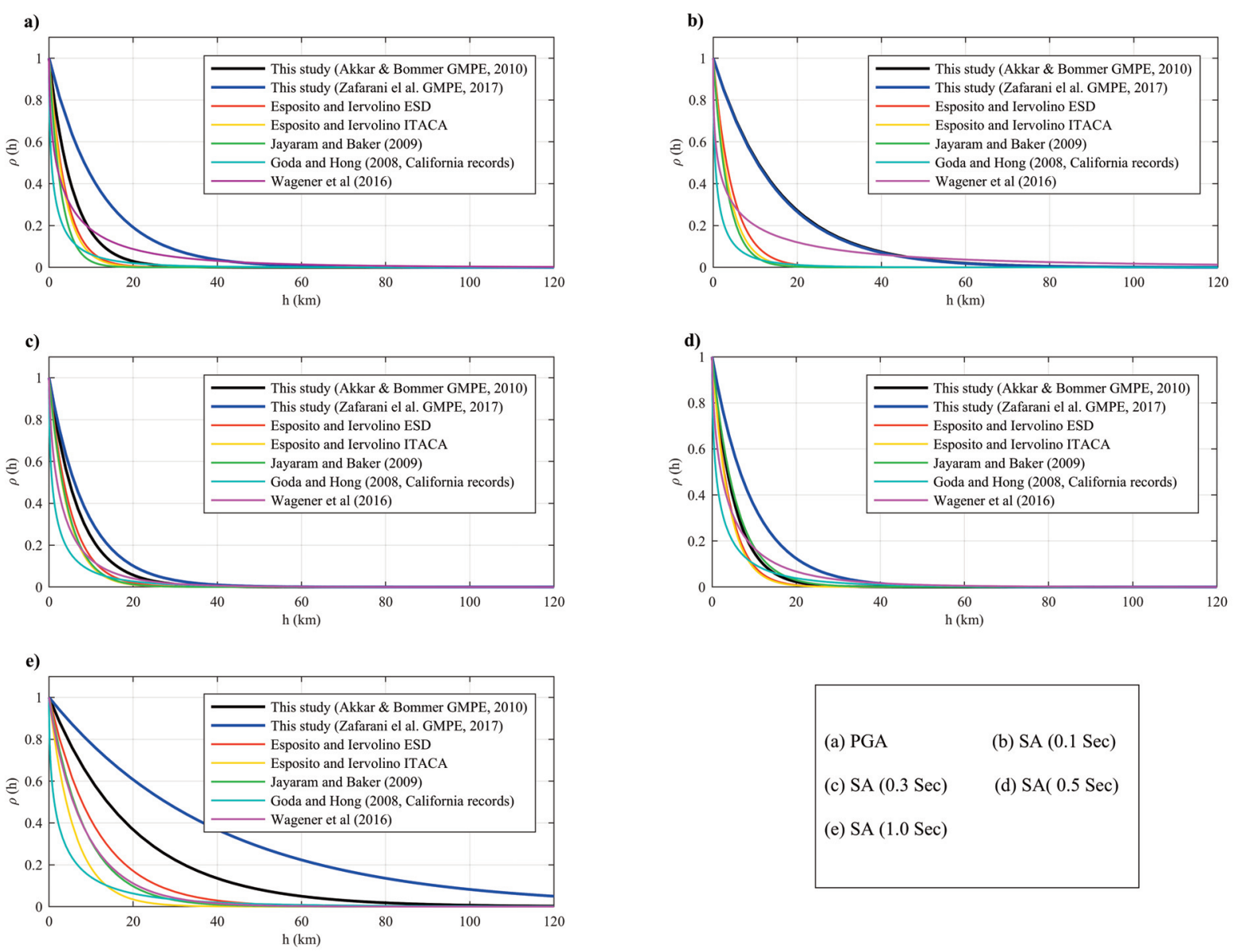

Figure 8. Comparison between correlation function $(\rho(\mathrm{h})$ )fitted to the Sarpol-e-Zahab earthquake data with using two different GMPEs and those models from Esposito and Iervolino [2012], Jayaram and Baker [2009], Goda and Hong [2008] and Wagener et al. [2016] at different periods a) $\mathrm{T}=0 \mathrm{~s}, \mathrm{~b}) \mathrm{T}=0.1 \mathrm{~s}, \mathrm{c}$ ) $\mathrm{T}=0.3 \mathrm{~s}, \mathrm{~d}$ ) $\mathrm{T}=0.5 \mathrm{~s}$ and e) $\mathrm{T}=1.0 \mathrm{~s}$. 

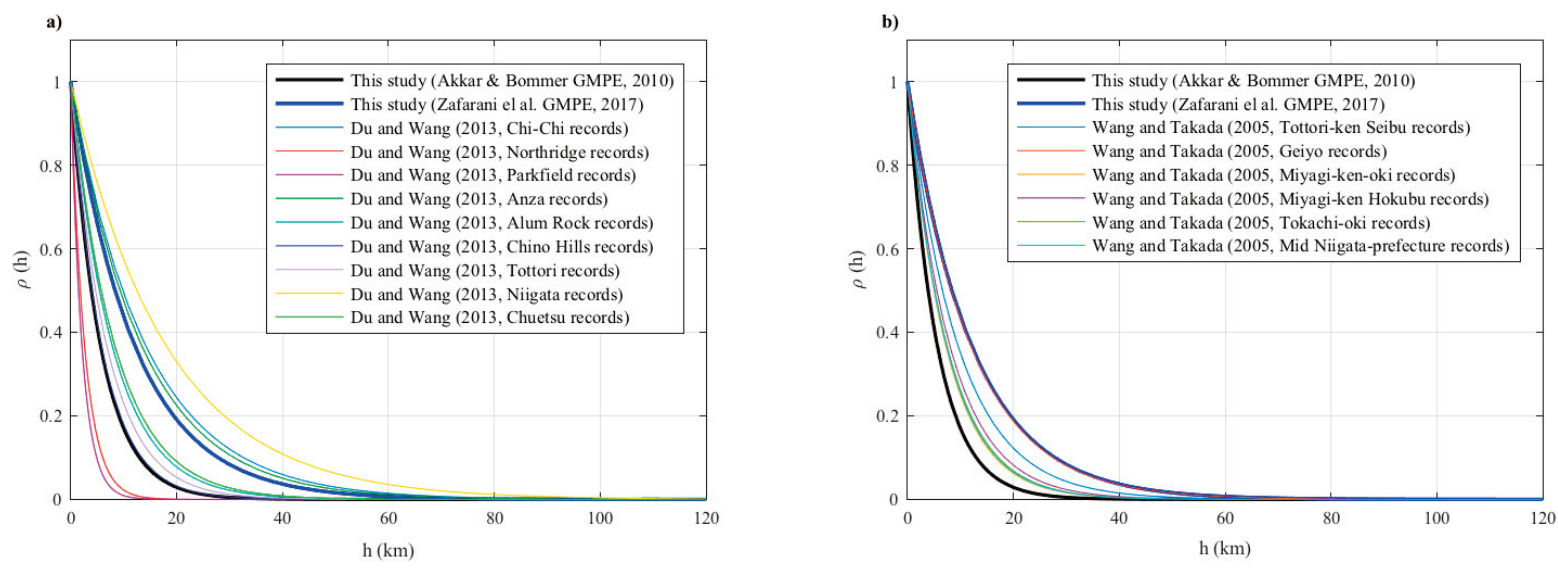

Figure 9. Comparison of correlation models of PGA in this study with a) Du and Wang [2013] and b) Wang and Takada [2005].

\section{Conclusions}

The spatial correlation models are proposed for western Iran region based on the Sarpol-e-Zahab earthquake and its aftershocks data (36 seismic events). Evaluation of the spatial correlation for the horizontal component of spectral acceleration (SA) at different spectral periods has been performed using geostatistical tools. Based on the results, an exponential function was selected for the provided models. A similar trend of correlation Ranges for the horizontal component of ground motion has been observed in comparison with other studies. The results show that the obtained Ranges can be considered in three distinct parts. The first and third segments have an increasing trend although the trend in the second one decreases with increasing spectral period. The Ranges increase up to $0.1 \mathrm{~s}$ and more than $0.5 \mathrm{~s}$ while the Ranges decrease in the period of 0.1 to $0.5 \mathrm{~s}$. As it is clear, there is the strong regional dependency in the models, which implies that the local correlation models should use for investigation of damage patterns caused by the Sarpol-e-Zahab earthquake. According to the model developed in this study, there is strong spatial correlation along with the Sarpol-e-Zahab earthquake ground motions. For that reason, this model can be employed in local risk assessments studies for lifeline systems or distributed structures.

Acknowledgements. The authors acknowledge the Building and Housing Research Centre of Iran for providing them with the accelerograms and shear-wave velocities used in the current study.

\section{References}

Akkar, S., and J.J. Bommer (2010).Empirical equations for the prediction of PGA, PGV, and spectral accelerations in Europe, the Mediterranean region, and the Middle East. Seismol. Res. Letts, 81(2), 195-206.

Bazzurro, P. and N. Luco (2007).Effects of different sources of uncertainty and correlation on earthquake-generated losses, Austr. J. Civil Eng., 4(1), 1-14.

Boore, D. M., J. F. Gibbs, W. B. Joyner, J. C. Tinsley and D. J. Ponti (2003). Estimated ground motion from the 1994 Northridge, California, earthquake at the site of the Interstate 10 and La Cienega Boulevard bridge collapse, West Los Angeles, California, Bull. Seism. Soc. Am., 93(6), 2737-2751.

Chen, Y., and J. Baker (2018). Spatial correlation in Cybershake physics-based ground motions simulationspreliminary results. In 11th US National Conf. on Earthquake Engineering Integrating Science, Engineering and Policy.

Chen, L. and E. Faccioli (2013). Single-station standard deviation analysis of 2010-2012 strong-motion data from the Canterbury region, New Zealand, Bull. Earthq. Eng., 11(5), 1617-1632. 


\section{Hamid Zafarani et al.}

Cimellaro, G. P., A. De Stefano \& A. M. Reinhorn (2011). Intra-event spatial correlation of ground motion using L'Aquila earthquake ground motion data, In 3rd ECCOMAS thematic conference on computational methods in structural dynamics and earthquake engineering, Corfu, Greece, 3091-3108.

Cressie, N. and D. M. Hawkins (1980). Robust estimation of the variogram: I J. Inter. Assoc. Math. Geo.,12(2), 115125.

Cressie, N. A. (1993). Statistics for spatial data: Wiley series in probability and mathematical statistics, doi:10.1002/9781119115151

Crowley, H., Bommer, J. J., Pinho, R., and Bird, J. (2005). The impact of epistemic uncertainty on an earthquake loss model, Earthq. Eng. Struct. Dyn., 34(14), 1653-1685.

Crowley, H., J. J. Bommer and P. J. Stafford (2008a). Recent developments in the treatment of ground-motion variability in earthquake loss models, J. Earthq. Eng., 12(S2), 71-80.

Crowley, H., P. J. Stafford and J. J. Bommer (2008b). Can earthquake loss models be validated using field observations?,J. Earthq. Eng., 12(7), 1078-1104.

$\mathrm{Du}, \mathrm{W}$. and G. Wang (2013). Intra-event spatial correlations for cumulative absolute velocity, Arias intensity, and spectral accelerations based on regional site conditions, Bull. Seism. Soc. Am., 103(2A), 1117-1129.

Esposito, S. and I. Iervolino (2011). PGA and PGV spatial correlation models based on European multievent datasets, Bull. Seism. Soc. Am., 101(5), 2532-2541.

Esposito, S. and I. Iervolino (2012). Spatial correlation of spectral acceleration in European data, Bull. Seism. Soc. Am., 102(6), 2781-2788.

Farzanegan, E.S., A. Eshaghi, M. Mirsanjari, H. Abdollahi and H. MirzaeeAlavijeh (2017). Report of the november 12, 2017 sarpol-e zahab, kermanshah province earthquake.

Goda, K. and H. P. Hong (2008a).Spatial correlation of peak ground motions and response spectra, Bull. Seism. Soc. Am., 98(1), 354-365.

Goda, K. and H. P. Hong (2008b).Estimation of seismic loss for spatially distributed buildings, Earthq. Spec., 24(4), 889-910.

Goda, K. and G. M. Atkinson (2010). Intraevent spatial correlation of ground-motion parameters using SK-net data, Bull. Seism. Soc. Am., 100(6), 3055-3067.

Goda, K. (2011). Interevent Variability of Spatial Correlation of PeakGround Motions and Response Spectra, Bull. Seism. Soc. Am.,101(5), 2522-2531.

Heresi, P. and E. Miranda (2018).Uncertainty in intraevent spatial correlation of elastic pseudo-acceleration spectral ordinates, Bull. Earthq. Eng., 1-17.

Jayaram, N. and J. W. Baker (2009). Correlation model for spatially distributed ground-motion intensities, Earthq.Eng.Struct. Dyn.,38(15), 1687-1708.

Kotha, S. R., D. Bindi and F. Cotton (2016).Partially non-ergodic region specific GMPE for Europe and Middle-East, Bull.Earthq. Eng., 14(4), 1245-1263.

Landwehr, N., N. M. Kuehn, T. Scheffer and N. Abrahamson (2016). A nonergodic ground-motion model for California with spatially varying coefficients, Bull. Seism. Soc. Am., 106(6), 2574-2583.

Lee, R. and A. S. Kiremidjian (2007). Uncertainty and correlation for loss assessment of spatially distributed systems, Earthq. Spect., 23(4), 753-770.

Loth, C. and J. W. Baker (2013).A spatial cross-correlation model of spectral accelerations at multiple periods, Earthq.Eng.Struct. Dyn.,42(3), 397-417.

Markhvida, M., L. Ceferino, and J. W. Baker (2018).Modeling spatially correlated spectral accelerations at multiple periods using principal component analysis and geostatistics, Earthq. Eng. Struct. Dyn.,47(5), 1107-1123.

McVerry, G. H., D. A. Rhoades and W. D. Smith (2004, August).Joint hazard of earthquake shaking at multiple locations. In Proceedings of 13th world conference on earthquake engineering, Vancouver, Canada.

Park, J., P. Bazzurro and J. W. Baker (2007). Modeling spatial correlation of ground motion intensity measures for regional seismic hazard and portfolio loss estimation, Applications of statistics and probability in civil engineering, 1-8.

Pavel, F. and R. Vacareanu (2016). Spatial Correlation of Ground Motions from Vrancea (Romania) Intermediate-Depth Earthquakes, Bull. Seism. Soc. Am., 107(1), 489-494.

Soghrat, M. R. and M. Ziyaeifar (2017).Ground motion prediction equations for horizontal and vertical components of acceleration in Northern Iran, J. Seism., 21(1), 99-125. 
Sokolov, V. and F. Wenzel (2011). Influence of spatial correlation of strong ground motion on uncertainty in earthquake loss estimation,Earthq. Eng. Struct.Dyn., 40(9), 993-1009.

Sokolov, V. and F. Wenzel (2013). Further analysis of the influence of site conditions and earthquake magnitude on ground-motion within-earthquake correlation: analysis of PGA and PGV data from the K-NET and the KiKnet (Japan) networks, Bull. Earthq. Eng., 11(6), 1909-1926.

Wagener, T., K. Goda, M. Erdik, J. Daniell and F. Wenzel (2016). A spatial correlation model of peak ground acceleration and response spectra based on data of the Istanbul earthquake rapid response and early warning system, Soil Dyn. Earthq. Eng., 85, 166-178.

Wald, D. J., V. Quitoriano, T. H. Heaton, H. Kanamori, C. W. Scrivner and C. B. Worden (1999b). TriNet 'ShakeMaps': Rapid generation of peak ground motion and intensity maps for earthquakes in southern California, Earthq. Spec., 15, 537-555.

Wang, G. and W. Du (2013). Spatial Cross-Correlation Models for Vector Intensity Measures (PGA, Ia, PGV, and SAs) Considering Regional Site Conditions. Bull. Seism. Soc. Am., 103(6), 3189-3204.

Wang, M. and T. Takada (2005).Macrospatial correlation model of seismic ground motions, Earthq.Spect.,21(4), 1137-1156.

Wang, M. and T Takada (2005).Macro-spatial correlation model of seismic ground motions.ICOSSAR 2005, G. Augusti, G.I. Schuëller, M. Ciampoli (eds),Millpress, Rotterdam, ISBN 9059660404

Wesson, R. L. and D. M. Perkins (2001). Spatial correlation of probabilistic earthquake ground motion and loss, Bull. Seism. Soc. Am., 91(6), 1498-1515.

Worden, C. B., E. M. Thompson, J. W. Baker, B. A. Bradley, N. Luco and D. J. Wald (2018). Spatial and Spectral Interpolation of Ground-Motion Intensity Measure Observations, Bull. Seism. Soc. Am.,108(2), 866-875.

Zafarani, H., L. Luzi, G. Lanzano, M. R. Soghrat (2017). Empirical equations for the prediction of PGA and pseudo spectral accelerations using Iranian strong-motion data, J. Seism., 22(1), 263-285.

Zafarani, H. and M. R. Soghrat (2017). Single-Station Sigma for the Iranian Strong Motion Stations, Pure Appl. Geoph., 174(11), 4077-4099.

Zafarani, H. and M. R. Soghrat (2017). A selected dataset of the Iranian strong motion records, Nat. Haz., 86(3), 1307-1332.

Zerva, A. and V. Zervas (2002). Spatial variation of seismic ground motions: an overview. Appl. Mech. Rev., 55(3), 271-297.

*CORRESPONDING AUTHOR: Hamid ZAFARANI,

International Institute of Earthquake Engineering and Seismology (IIEES),

No. 26, Arghavan St., North Dibajee, Farmanieh,

P.O. Box: 19395/3913, Tehran, Iran

Phone: +98-21-22803647

Fax: +98-21-22833865

e-mail: h.zafarani@iiees.ac.ir | hamzafarani@yahoo.com

(C) 2020 the Istituto Nazionale di Geofisica e Vulcanologia.

All rights reserved 